\title{
A CIDADE MARAVILHOSA E AS CIDADES DO ABANDONO - O VERSO E O REVERSO DAS POLÍTICAS PÚBLICAS DE SEGURANÇA NA REGIÃO METROPOLITANA DO RIO DE JANEIRO
}

Enderson Albuquerque ${ }^{1}$

Resumo: $O$ presente trabalho tem por objetivo analisar as políticas de segurança pública no interior da Região Metropolitana do Rio de Janeiro (RMRJ). Para tanto, analisamos historicamente como a violência funcionou como fator estrutural para conformação territorial da Baixada Fluminense. Posteriormente, investigamos a espacialização geográfica da Unidade de Polícia Pacificadora (UPP) na RMRJ, as ações executadas durante o período de intervenção militar na área de segurança no Estado e o número de policiais lotados nos batalhões metropolitanos e sua relação com o total de habitantes atendidos. Os dados apontaram que, mesmo os municípios baixadianos apresentando índices criminais mais elevados que a cidade do Rio de Janeiro, a região é preterida em intervenções da área de segurança.

Palavras-chave: Região Metropolitana do Rio de Janeiro. Baixada Fluminense. Violência.

\section{THE WONDERFUL CITY AND THE ABANDONED CITIES - THE BACK AND REVERSE OF PUBLIC SECURITY POLICIES IN THE METROPOLITAN REGION OF RIO DE JANEIRO}

Abstract: The present work aims to analyze public security policies in the interior of the Metropolitan Region of Rio de Janeiro (RMRJ). To this end, we have historically analyzed how violence functioned as a structural factor for the territorial shape of the Baixada Fluminense. Subsequently, we investigated the geographic spatialization of the Pacifying Police Unit (UPP) in RMRJ, actions carried out during the period of military intervention in the area of security in the State and the number of police stationed in the metropolitan battalions and their relationship with the total of inhabitants served. The data showed that, even the low-income municipalities with higher criminal rates than the city of Rio de Janeiro, the region is neglected in public security.

Keywords: Metropolitan Region of Rio de Janeiro. Baixada Fluminense. Violence.

\section{LA MARAVILLOSA CIUDAD Y LAS CIUDADES ABANDONADAS: EL RESPALDO Y LA REVERSA DE LAS POLÍTICAS DE SEGURIDAD PÚBLICA EN LA REGIÓN METROPOLITANA DE RÍO DEJANEIRO}

Resumen: El presente trabajo tiene como objetivo analizar las políticas de seguridad pública en el interior de la Región Metropolitana de Río de Janeiro (RMRJ). Con este fin, hemos analizado históricamente cómo la violencia funcionó como un factor estructural para la forma territorial de la Baixada Fluminense. Posteriormente, investigamos la espacialización geográfica de la Unidad de Policía Pacificadora

\footnotetext{
1 Universidade do Estado do Rio de Janeiro (UERJ), Departamento de Geografia, Rio de Janeiro, Brasil, endersonalbuquerque@yahoo.com.br, https://orcid.org/0000-0001-7807-1851
} 
(UPP) en RMRJ, acciones llevadas a cabo durante el período de intervención militar en el área de seguridad en el Estado y el número de policías estacionados en los batallones metropolitanos y su relación con el total de habitantes atendidos. Los datos mostraron que, incluso en los municipios de bajos ingresos con tasas criminales más altas que la ciudad de Río de Janeiro, la región está descuidada en las intervenciones de seguridad pública.

Palabras clave: Región Metropolitana de Río de Janeiro. Baixada Fluminense. Violencia.

\section{A violência como estruturante para a conformação territorial da Baixada Fluminense}

Os municípios da Baixada Fluminense tiveram seu processo de ocupação populacional atrelada à expansão fundiária do então Distrito Federal e sua dinâmica econômica. Em consonância ao projeto nacional, na década de 1970 a Baixada Fluminense apresentou um acelerado processo de urbanização, materializado juridicamente com a criação da Região Metropolitana do Rio de Janeiro em 1973, oficializada por meio da lei Complementar Federal no 20/1974. A área metropolitana fluminense nasceu formada por dois estatutos jurídicos distintos, o do Estado da Guanabara e o do Estado do Rio de Janeiro. Nesse contexto, mesmo após a transferência da capital do país para Brasília em 1960 e posterior criação da RM, continuaram vinculados à cidade do Rio de Janeiro. Em virtude dessas condições, a região expressa de forma cristalina sua condição periférica no bojo da RMRJ.

Com efeito, a Baixada Fluminense se inscreve como integrante periférica da área metropolitana fluminense, conforme ilustra a Figura 1. Tal condição periférica se expressa, também, no perfil socioeconômico de sua população e, de maneira mais perversa, nas políticas públicas destinadas aos municípios que a compõem. No caso específico desta periferia baixadiana, soma-se ainda a violência, a qual acompanha a construção imagética dessa região. Assim, analisaremos as políticas públicas de segurança distintas executadas entre os municípios metropolitanos em sua relação com a disseminação da violência como ferramenta política na Baixada Fluminense. 
Figura 01 - Municípios componentes da Baixada Fluminense e da Região Metropolitana do Rio de Janeiro

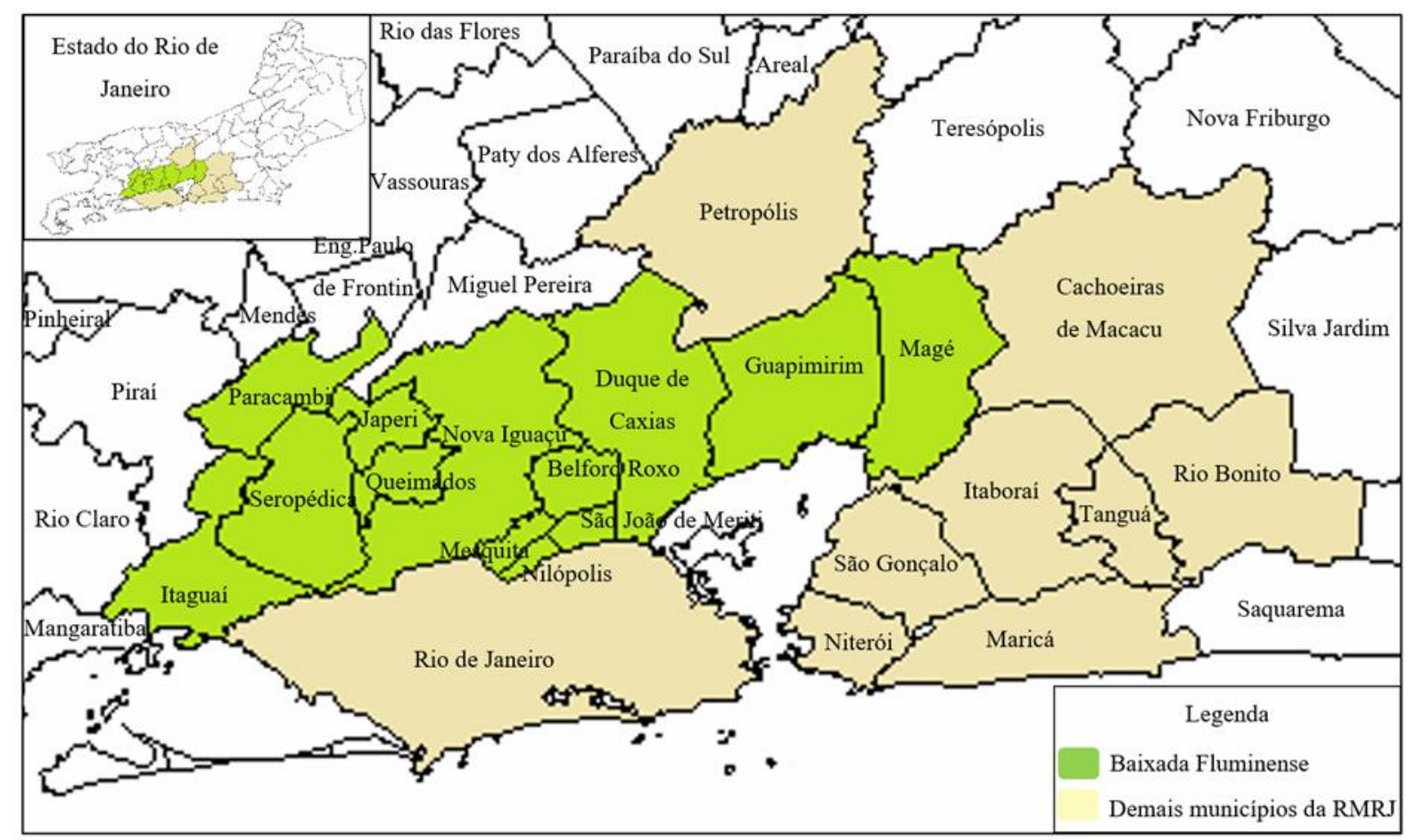

Fonte: O autor (2020)

Entenderemos como violência uma ação voluntária (STOPPINO, 1998) impetrada sobre um indivíduo ou grupo de indivíduos visando uma sanção de ordem física ou psíquica - medo, sofrimento, dor (ZALUAR, 1999) -, a qual tem por finalidade última impor certo comportamento ao (s) agredido (s) que os impeça de discordar do agressor (ODALIA, 1991). Essa ação se caracteriza, sobretudo, por ocorrerem às margens da legalidade instituída (OLIVEIRA, 2016).

A Baixada Fluminense não possui exclusividade no tocante à existência da violência. Outras periferias nacionais padecem do mesmo mal. Ainda que notadamente consista em um fenômeno urbano e metropolitano, conforme indica Anuário Brasileiro de Segurança Pública de 2019 (FORÚM BRASILEIRO DE SEGURANÇA PÚBLICA, 2019), a violência encontra-se presente em diferentes escalas e suas implicações são distintas quando considerados os espaços nos quais ela se manifesta. A violência praticada em áreas nobres tem estreita ligação com atentados contra a propriedade - assaltos a residências, roubos de carros e objetos pessoais de alto valor. Já em áreas periféricas, somam-se a essas formas de violência as praticadas contra a integridade física, como os homicídios. Assim, enquanto a violência contra a propriedade existente em áreas nobres em regra não 
objetiva a dominação territorial daquele espaço, a violência em áreas periféricas permite a transmutação de um ato imposto à integridade física e mental de alguém em um projeto de poder político sobre aquele espaço. Nesse sentido, "por mais que a imputação do ato violento, juridicamente, seja individual, sua operacionalidade se insere numa rede de ações, em escala coletiva, de amplitude e diversidade que atravessa os indivíduos e se ancora no social" (ALVES, 2015, p. 4-5).

O processo de transmutar violência em poder político na Baixada Fluminense passou a ser observado com maior nitidez a partir do início do século $X X$, aprimorando-se a partir da segunda metade desse período. Para Alves (1994, p. 10), em um primeiro momento, a violência

\begin{abstract}
esteve associada à atuação das milícias vinculadas às empresas e grupos loteadores que retalhavam as terras de acordo com a resistência dos ocupantes anteriores. Estes, por sua vez, respondiam, em casos extremos, de forma armada, iniciando os conflitos que transformaram a Baixada numa área conflagrada. Neste mesmo período, os caciques do poder local passaram a recorrer à truculência, herdada do coronelismo rural, na solução da crise hegemônica originada na recomposição da economia em bases urbanas.
\end{abstract}

Alves identifica no processo de adensamento populacional da Baixada Fluminense a manifestação inicial de uma violência mais ostensiva, a qual guardava efetiva ligação com o coronelismo rural. Por essa conjuntura sociopolítica, relações sociais comuns em áreas rurais do século XIX, como o coronelismo, ainda encontravam ecos no início do adensamento populacional da Baixada Fluminense no século seguinte.

O domínio territorial construídos por esses agentes, por extensão lhe conferiu uma autoridade extraoficial sobre esse espaço. À revelia das forças de segurança oficiais ou a partir de seu consentimento, os "coronéis" da Baixada Fluminense foram paulatinamente elaborando as leis, proferindo as sentenças e promovendo as execuções - das sentenças e dos sentenciados. As tensões geradas por esse processo resultaram em transformações significativas para esse recorte espacial. Em um cenário de instabilidade quanto aos limites da propriedade fundiária, a violência passou a funcionar como um mecanismo efetivo para demarcação dessas "fronteiras" privadas. A associação da Baixada Fluminense com a violência nasceu dessa tensão gerada entre os "posseiros" e aqueles que se autodenominavam proprietários das terras. Como consequência, ao passo em que ditava a lógica fundiária, a coerção física também inaugurava um território do medo na Baixada Fluminense. 
Posterior a esse movimento e aliada às políticas públicas de segurança ineficientes, a violência na Baixada Fluminense conheceu outro patamar de sofisticação. Esse novo arranjo promoveu a "modernização" da máquina de coerção, inaugurando o segundo momento de conflagração da violência no espaço baixadiano. De acordo com Alves (1994, p. 10),

transposta esta primeira fase de ocupação das suas terras e rearranjo do poder político, a Baixada conhecerá o período que a elevou à categoria de "região mais violenta do mundo". Os aparatos para oficiais e oficiais de extermínio passam a "desovar" os "ovos" gerados no processo de retração do capital e de crise econômica somado à formação de centros-periferias e, consequentemente, da guerra de classe dentro das sub-regiões da Baixada. A violência do extermínio foi assim convocada para garantir a manutenção dos interesses econômicos e políticos dos que tinham na Baixada seus grandes negócios.

O cenário apontado pelo autor ajudou na consolidação dos grupos paramilitares. Alves (2015, p. 7) sintetiza a natureza desses grupos de extermínio e sua forma de atuação no decorrer do século XX. Para ele, a articulação que permitiu a ascensão desses grupos foi construída no período do golpe civil-militar de 1964 "a partir da articulação de três elementos: 1) o aparato policial que compõe os grupos e que assassina; 2) o financiamento por grupos econômicos; e 3) o suporte de políticos que garantem o funcionamento do grupo e se valem dos seus serviços".

A ditadura militar inaugurou, assim, um novo momento no tocante à prática da coerção física na Baixada Fluminense. Se a disputa fundiária marcou a primeira fase cronológica da violência como força política, a questão ideológica, juntamente com outras disputas territoriais de variadas ordens, permeou a segunda fase. Ancorados no lema "bandido bom é bandido morto", nesse período histórico, os grupos de extermínio torturavam e matavam pessoas que cometiam delitos como roubos. Ancorado no lema "Brasil: ame-o ou deixe-o", os militares torturavam e matavam pessoas que cometiam o delito de discordar do regime. O diferencial entre essas duas formas de sanções físicas é que a primeira era executada por agentes públicos de segurança de forma ilegal, mas, em maior ou menor grau, com o consentimento do Estado, já a segunda era operada diretamente pelo Estado.

Ainda no início da década de 1980 os grupos de extermínio passaram a ser compostos, também, por agentes não vinculados ao aparato estatal de segurança. Apesar da vitalidade desse território coercitivo na Baixada Fluminense, a execução de um projeto de poder por meio da violência sofreu nova alteração a partir da 
década de 1980 por meio desse novo perfil de agentes. Para Alves (2005, p. 24), esse processo se deveu à

\begin{abstract}
inovação no funcionamento deste aparato de execuções sumárias. Sofrendo com a maior exposição e cobrança da mídia, numa conjuntura de abertura política, os grupos de extermínio iniciaram um processo de autonomização frente ao aparelho policial. Progressivamente, policiais militares e civis se transformaram em agenciadores dos serviços destes grupos, mantendo o envolvimento, mas lidando agora com um mercado mais competitivo, onde vários outros grupos atuavam.
\end{abstract}

Em paralelo a esse movimento aludido por Alves, o enfraquecimento do regime militar frente às demandas democráticas alterou a relação entre os agentes responsáveis pela violência e sua proximidade ao aparelho estatal. Temendo o fim da impunidade dos crimes acobertados antes pelos militares, os policiais que atuavam nos grupos de extermínio mantiveram sua atuação, porém de maneira menos ostensiva e passaram a buscar apoio em membros da sociedade civil. Tal movimento pode ser entendido como precursor das chamadas milícias, as quais dominam partes da zona oeste da cidade do Rio de Janeiro e da Baixada Fluminense no período atual.

Assim, emerge a terceira fase da violência como ferramenta sociopolítica na região, na qual os agentes executores da violência sofisticam sua atuação e passam a compor diretamente os poderes legislativo e executivo, seja de forma direta ou por intermédio de pessoas ligadas aos seus interesses. "Com efeito, na Baixada Fluminense ocorreu a 'politização' da violência, de modo que os mecanismos de repressão foram convertidos em instrumentos políticos (ALBUQUERQUE, 2020, p. 193).

\title{
O núcleo e a periferia - desigualdades referentes à segurança pública metropolitana
}

Para fins de gestão do espaço fluminense, por meio do Decreto Estadual no․ 41.930 de 26 de novembro de 2009, o ISP (Instituto de Segurança Pública), regionalizou o estado em 4 grandes regiões. Cabe ressaltar que a Baixada Fluminense não existe oficialmente enquanto Região Administrativa de governo. Contudo, quando a Secretaria de Segurança Pública a institui como uma região, tal fato assinala que sua existência só ganha contornos de "realidade" se entendida a partir das atrocidades criminais que vitimizam seus moradores. Desse modo, a violência oficializa esta região para os órgãos governamentais. Todavia, embora 
para a Secretaria de Segurança Pública o entendimento de Baixada Fluminense passe, inequivocamente pela questão da violência, as políticas públicas ofertadas a essa sub-região expõe uma distinção estratégica clara quando comparada ao núcleo metropolitano. Essa distinção se reflete na geografia das UPPs - Unidades de Polícia Pacificadora - (Figura 2) e na distribuição de agentes de segurança entre os batalhões da RMRJ.

Figura 02 - Espacialização das UPPs no estado do Rio de Janeiro

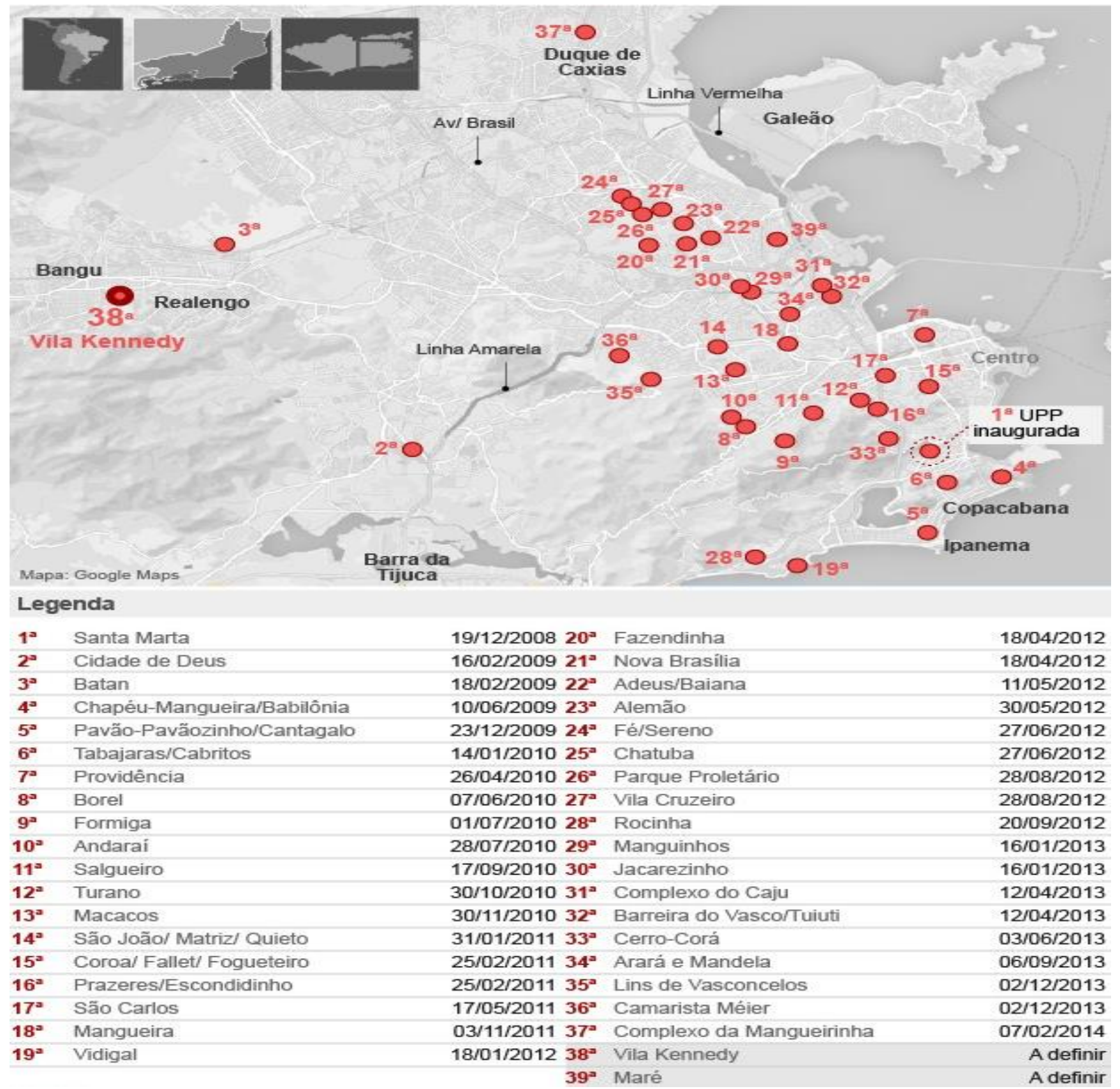

Fonte: G1. Disponível em: <http://g1.globo.com/rio-de-janeiro/noticia/2014/03/policia-prende-mais-de100-pessoas-desde-o-inicio-do-cerco-marerio.html . Acesso em: 11/03/2019. 
As UPPs, intervenção iniciada em dezembro de 2008, de acordo com o site oficial do projeto ${ }^{2}$ tem como objetivo "devolver à população local a paz e a tranquilidade públicas, necessárias ao exercício e desenvolvimento integral da cidadania. Contribuir para quebrar a lógica de "guerra" existente no Estado do Rio de Janeiro". Embora tenha como um dos seus objetivos "quebrar a lógica de 'guerra' existente no Estado do Rio de Janeiro", as UPPs se caracterizam por serem majoritariamente carioca em sua dimensão espacial. Em 2018, das 37 favelas que contavam com a instalação de Unidades de Polícia Pacificadora, 36 estavam situadas nos limites da cidade do Rio de Janeiro e apenas uma estava instalada em município da Baixada Fluminense, a UPP do Complexo da Mangueirinha em Duque de Caxias.

Em razão desta espacialização, em alguma medida, as UPPs foram classificadas não como uma política de segurança pública, mas como uma política tão somente, a qual foi colocada em curso pelo governador Sérgio Cabral (20072014). Essa visão se deveu a maneira pela qual essa política foi implantada exclusivamente em favelas cariocas, acarretando na diminuição drástica dos índices de criminalidade nos limites territoriais da cidade do Rio de Janeiro e deslocamento de "mão de obra" e armamentos para as favelas da Baixada Fluminense e demais municípios metropolitanos como Niterói e São Gonçalo.

A geografia das UPPs não é o único exemplo da seletividade espacial dos fixos de segurança pública no contexto da RMRJ. A relação numérica entre o número de habitantes e de policiais militares responsáveis pelo patrulhamento em determinadas áreas, revela, mais uma vez, a desigualdade no comparativo entre a cidade do Rio de Janeiro e alguns municípios da Baixada Fluminense.

Considerando a população estimada para os respectivos municípios metropolitanos aferida pelo IBGE para o ano de 2017 e o número de policiais lotados em cada batalhão, conseguido por meio de pesquisa de campo realizada em junho de 2018 no Quartel General da Polícia Militar, a Tabela 1 registra o número de policias lotados e o número de agentes considerado como ideal pelo Ministério Público em cada área.

\footnotetext{
${ }^{2}$ Disponível em http://www.upprj.com/index.php/as_upps.
} 
Tabela 01 - Relação entre o número de policiais militares e habitantes entre os municípios da RMRJ (2018)

\begin{tabular}{|c|c|c|c|c|c|c|}
\hline \multirow{2}{*}{ Municípios } & \multicolumn{2}{|c|}{$\begin{array}{c}\text { Número de } \\
\text { Policiais } \\
\text { Militares }\end{array}$} & \multirow[t]{2}{*}{ População } & \multicolumn{2}{|c|}{$\begin{array}{l}\text { Habitantes por } \\
\text { policial }\end{array}$} & \multirow{2}{*}{$\begin{array}{c}\text { Diferença } \\
\text { entre o } \\
\text { número } \\
\text { atual e o } \\
\text { ideal de } \\
\text { policiais }\end{array}$} \\
\hline & 2018 & Ideal & & 2018 & Ideal & \\
\hline Belford Roxo & 349 & 542 & 495.783 & $1.420,58$ & 914,72 & $35,60 \%$ \\
\hline Duque de Caxias & 813 & 1.690 & 890.997 & $1.095,93$ & 527,21 & $51,89 \%$ \\
\hline Magé e Guapimirim & 359 & 542 & 295.341 & 882,67 & 544,90 & $33,76 \%$ \\
\hline Niterói e Maricá & 978 & 1.145 & 652.036 & 666,70 & 569,46 & $14,58 \%$ \\
\hline $\begin{array}{l}\text { Mesquita, Nova Iguaçu e } \\
\text { Nilópolis }\end{array}$ & 899 & 1.638 & 1.128 .255 & $1.255,01$ & 688,80 & $45,11 \%$ \\
\hline São Gonçalo & 929 & 1.223 & 1.049 .826 & $1.130,06$ & 858,40 & $24,03 \%$ \\
\hline São João de Meriti & 440 & 994 & 460.461 & $1.046,50$ & 463,24 & $55,73 \%$ \\
\hline $\begin{array}{l}\text { Seropédica, Itaguaí, Paracambi, } \\
\text { Queimados e Japeri }\end{array}$ & 475 & 700 & 503.855 & $1.060,74$ & 719,79 & $32,14 \%$ \\
\hline $\begin{array}{l}\text { Cachoeiras de Macacu, Tanguá, } \\
\text { Rio Bonito e Itaboraí }\end{array}$ & 451 & 541 & 380.684 & 844,08 & 703,66 & $16,63 \%$ \\
\hline Baixada Fluminense & 3.335 & 6.106 & 3.774 .692 & $1.131,84$ & 618,19 & $45,38 \%$ \\
\hline Demais municípios da RMRJ & 2.358 & 2.909 & 2.082 .546 & 883,18 & 715,90 & $18,94 \%$ \\
\hline Rio de Janeiro & 8.151 & 18.358 & 6.520 .266 & 799,93 & 355,17 & $55,59 \%$ \\
\hline
\end{tabular}

Fonte: Elaborado pelo autor a partir de dados coletados em pesquisa de campo.

O $39^{\circ}$ batalhão, responsável pelo patrulhamento do município de Belford Roxo, apresenta a menor relação de policiais por residentes: um policial para cada 1.420,58 habitantes. Apesar de esse batalhão, ser o responsável pela segurança de 200.000 pessoas a mais que o batalhão responsável pelos municípios de Magé e Guapimirim e Belford Roxo ter tido 209 homicídios enquanto Magé e Guapimirim somados tiveram em 2018 127, o número total de policiais considerados como ideal pelo MP para a área abrangida pelos dois batalhões é o mesmo: 542.

Considerando a defasagem entre o número de policiais lotados em cada batalhão em 2018 e o número ideal indicado pelo MP, a diferença em percentagem 
é mais elevada nos municípios de São João de Meriti e Duque de Caxias, com quase $54,0 \%$ de disparidade. Ou seja, esses dois batalhões tinham menos da metade do número de policiais indicado como ideal. A menor diferença corresponde ao 35 BPM, responsável pelos municípios de Cachoeiras de Macacu, Tanguá, Rio Bonito e Itaboraí, com apenas $14,6 \%$ de diferença entre o número real e o ideal. Convém salientar que esses municípios, embora pertençam à RMRJ pela divisão administrativa do governo do Estado do Rio de Janeiro, na divisão regional estabelecida pelo ISP eles pertencem ao Interior Fluminense.

No comparativo entre o núcleo metropolitano e suas "periferias geográficas", a cidade do Rio de Janeiro apresenta a maior diferença entre o número ideal de policiais e o número existente. Embora na capital houvesse um policial a cada 800 residentes em 2018, nos demais municípios metropolitanos havia um para cada 883 e na Baixada Fluminense um policial para cada 1.131 moradores. No espaço carioca a diferença entre o número real e o ideal é de 55,5\%, na Baixada Fluminense de 45,3\% e entre os demais municípios da RMRJ de 19\%. Dessa forma, mesmo contando com mais policiais por habitantes que suas periferias, a discrepância entre o número de policiais considerado como ideal em relação ao real é maior no município do Rio de Janeiro.

O Ministério Público entende como ideal uma relação menor entre o número de policiais militares e de população atendida para a capital quando se compara as demais áreas metropolitanas. Um policial a cada 355 habitantes para a cidade do Rio de Janeiro, por exemplo, é mais que o dobro do indicado como ideal para demais municípios da RMRJ, nos quais esse número é de um para 715 , e um número $42,5 \%$ superior ao considerado ideal para a Baixada Fluminense. Sobre a relação de policiais em comparação ao total populacional dos municípios, Ribeiro et al. (2005, p. 43), concluem que tal distorção evidencia "que o poder público dirige seus recursos de segurança pública preferencialmente para a capital e para alguns outros municípios, como Niterói, enquanto que o policiamento na Baixada é muito mais escasso, a despeito das altas taxas de homicídio observadas".

Os dados sobre a violência metropolitana até 2019 expressam numericamente as implicações dessas políticas desiguais no contexto da RMRJ. Para empreender essa análise, selecionamos três índices: letalidade, homicídio doloso e autos de resistência. Em alguma medida, as taxas de letalidade sintetizam as tipologias de violência existentes em um recorte espacial ao destacar as 
agressões que produzem óbitos. Nela está inclusa os dados referentes aos crimes violentos letais intencionais como os homicídios dolosos, homicídios decorrentes de oposição à intervenção policial, latrocínio (roubo seguido de morte) e lesão corporal seguida de morte.

A análise desses dados expõe claramente o desnível entre a Baixada Fluminense e as demais Grandes Regiões de Segurança Pública do Estado do Rio de Janeiro. Desde que a série histórica foi registrada levando em conta a Baixada Fluminense, apenas em 2002, quando foi superada pela Grande Niterói, essa região não apresentou os índices mais elevados no tocante às taxas de letalidade no Estado do Rio de Janeiro. No ano seguinte, 2003, essa taxa chegou a 70,4, a segunda maior da história recente do Estado - menor apenas que os 75,9 registrado pelo Rio de Janeiro em 1994. Embora a taxa de letalidade violenta na Baixada Fluminense em 2019 esse tenha diminuído sensivelmente no comparativo com o ano anterior, ainda assim esse indicador é o mais elevado do Estado, conforme registra o Gráfico 1.

Gráfico 01 - Taxa de letalidade violenta por grupo de 100 mil habitantes no Estado do Rio de Janeiro (1991-2019)

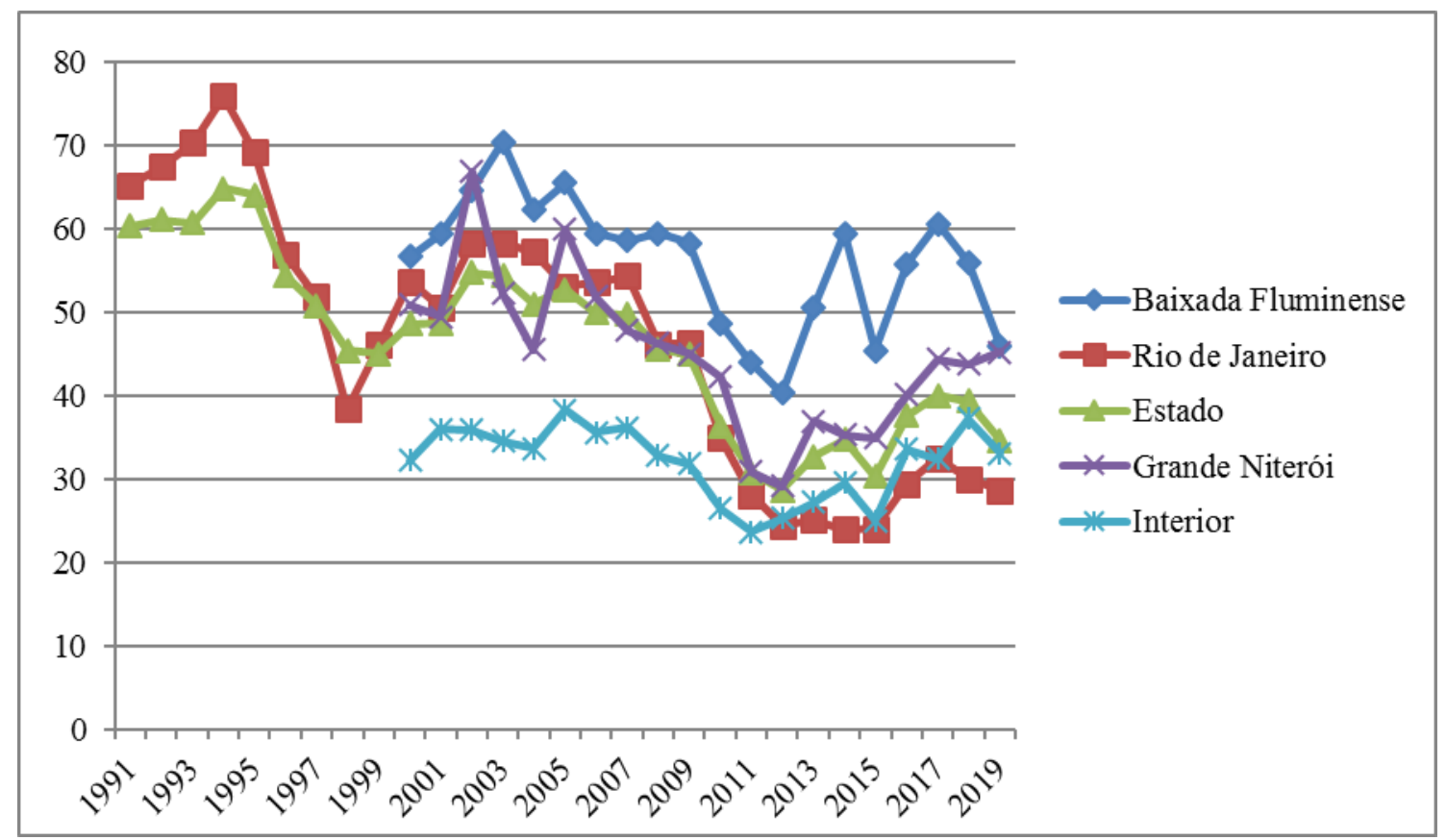

Fonte: Elaborado pelo autor a partir de dados do Instituto de Segurança Pública (ISP-RJ, 2020)

Em 2014 a cidade do Rio de Janeiro atingiu sua menor taxa de letalidade desde 1991, enquanto a Baixada Fluminense, nesse mesmo período, apresentou 
elevação: a taxa saltou de 50,6 em 2013 para 59,4 em 2014. Esse aumento também foi observado na Grande Niterói, outra Região que compõem a RMRJ. O período histórico de elevação das taxas de criminalidade na Baixada Fluminense, notadamente a partir dos anos 1980, é anterior ao espaço temporal abordado pelo Gráfico 1. Considerando as taxas de homicídios dolosos para o estado do Rio de Janeiro, a Baixada Fluminense é a região que apresenta os dados mais elevados no território fluminense, conforme destacado no Gráfico 2.

Gráfico 02 - Taxa de homicídio doloso por grupo de 100 mil habitantes no Estado do Rio de Janeiro (1991-2019)

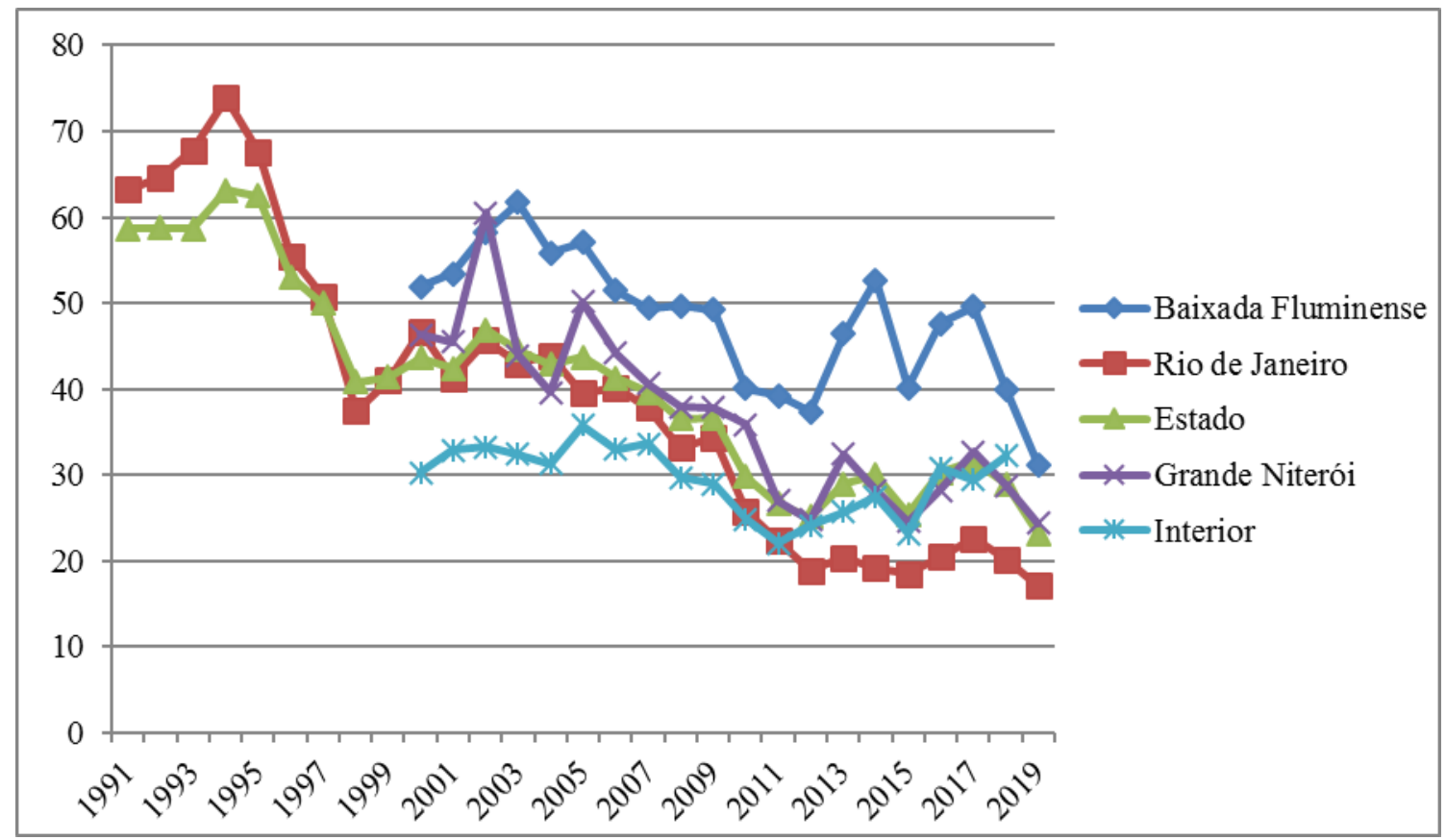

Fonte: Elaborado pelo autor a partir de dados do Instituto de Segurança Pública (ISP-RJ, 2020)

Assim como em relação aos dados relativos à letalidade, cumpre mencionar que as taxas de homicídios dolosos apresentaram uma queda a partir de 2009, voltando a subir somente em 2016 para o caso do município do Rio de Janeiro. Em contrapartida, essa dinâmica não se verificou na Baixada Fluminense. No período aludido, as taxas de letalidade e de homicídios dolosos inicialmente acompanharam a queda verificada na capital, porém, em 2013, esse indicador aumentou significativamente entre os municípios baixadianos. A taxa de letalidade atingiu o patamar 59,4 para cada cem mil habitantes em 2014 na Baixada Fluminense. $\mathrm{Na}$ cidade do Rio de Janeiro esse número foi de 24. Quanto aos homicídios dolosos, 
nesse mesmo ano a Baixada Fluminense apresentou uma taxa de 52,7, enquanto na capital a taxa ficou em 19,2.

Parte da explicação para essa distinção verificada no comparativo entre a cidade do Rio de Janeiro e as demais áreas da RMRJ pode estar relacionada com a política de criação das UPPs iniciadas no fim de 2008. Apurando os dados desse período e considerando a relação apenas entre a Baixada Fluminense e o município do Rio de Janeiro, se percebe essa dinâmica, a qual o Gráfico 3 remonta destacando as taxas de letalidade no período anterior e posterior à implantação das UPPs.

Gráfico 03 - Taxa de letalidade violenta por 100 mil habitantes considerando a Baixada Fluminense e a capital (2000-2019)

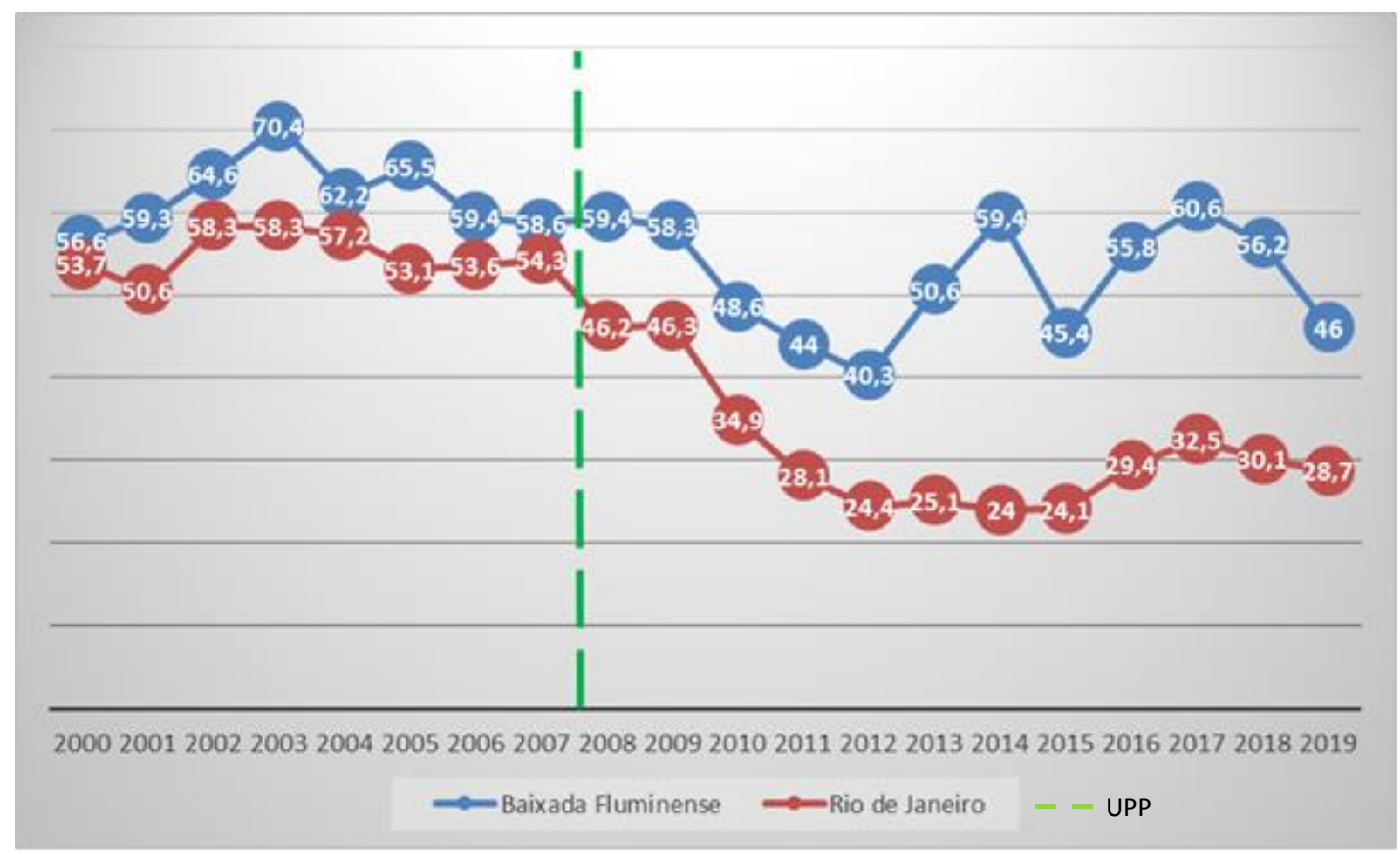

Fonte: Elaborado pelo autor a partir de dados do Instituto de Segurança Pública (ISP-RJ, 2020)

O Gráfico acima aponta que após a inauguração das Unidades de Polícia Pacificadoras as taxas comparativas de letalidade entre a Baixada Fluminense e o município do Rio de Janeiro passaram a apresentar números mais destoantes. Como exemplos díspares, em 2000, primeiro ano da série considerada, a diferença entre essa taxa para os dois recortes selecionados era de 2,9. Em 2014, ápice da disparidade entre esses espaços, a taxa de letalidade atingiu 59,4 para Baixada 
Fluminense e 24 para a cidade do Rio de Janeiro, perfazendo uma diferença de 35,4 . Todavia, a diferença entre a taxa média dessa tipologia criminal entre a Baixada Fluminense e a capital passou de 14,4 no período anterior à instalação das UPPs para 20,9 após sua implantação. Em ambos os espaços as taxas foram menores na média após as UPPs, contudo a diminuição foi mais acentuada na cidade do Rio de Janeiro.

Em razão da crise econômica do Estado do Rio de Janeiro, culminando em cortes orçamentários para a área de segurança pública, houve o enfraquecimento da política das UPPs. Como consequência desse esvaziamento, a partir de 2015 as taxas de letalidade absolutas na capital deixam de seguir sua trajetória de queda e se estabilizaram. O mesmo ocorreu com as taxas referentes à Baixada Fluminense, e assim, a disparidade entre os dois recortes se mantiveram.

Convém ressaltar que mesmo considerando os números absolutos das taxas de letalidade, esses dados apontam para uma concentração desse tipo de crime entre os municípios baixadianos. Mesmo com uma população $42 \%$ menor que o município do Rio de Janeiro, a Baixada Fluminense, a partir de 2013 e até 2018, superou a capital em números absolutos de crimes letais (Tabela 2).

Tabela 02 - Número absoluto de letalidade considerando a Baixada Fluminense e a capital (2000-2019)

\begin{tabular}{c|c|c}
\hline Ano & $\begin{array}{c}\text { Baixada } \\
\text { Fluminense }\end{array}$ & Rio de Janeiro \\
\hline \multicolumn{3}{|c}{ Antes das UPPs } \\
\hline 2000 & 1.915 & 3.147 \\
2001 & 2.022 & 2.984 \\
2002 & 2.219 & 3.465 \\
2003 & 2.437 & 3.495 \\
2004 & 2.169 & 3.231 \\
2005 & 2.300 & 3.286 \\
2006 & 2.104 & 3.354 \\
2007 & 2.091 & 3.354 \\
2008 & 2.135 & 2.877
\end{tabular}

\begin{tabular}{l|c|c}
\hline \multicolumn{1}{c|}{ Ano } & $\begin{array}{c}\text { Baixada } \\
\text { Fluminense }\end{array}$ & $\begin{array}{c}\text { Rio de } \\
\text { Janeiro }\end{array}$ \\
\hline \multicolumn{3}{c}{ Após as UPPs } \\
\hline 2009 & 2.112 & 2.902 \\
2010 & 1.776 & 2.205 \\
2011 & 1.617 & 1.783 \\
2012 & 1.489 & 1.554 \\
2013 & 1.881 & 1.613 \\
2014 & 2.218 & 1.552 \\
2015 & 1.702 & 1.562 \\
2016 & 2.100 & 1.909 \\
2017 & 2.301 & 2.131 \\
2018 & 2.142 & 1.978 \\
2019 & 1.173 & 1.909 \\
\hline
\end{tabular}

Fonte: Elaborado pelo autor a partir de dados do Instituto de Segurança Pública (ISP-RJ, 2020)

A Tabela 2 registra que em 2000 a Baixada Fluminense apresentou 1.915 casos de crimes letais, enquanto o município do Rio de Janeiro registrou 3.147. 
Nesse ano, somando os números totais de letalidade da Baixada Fluminense e da capital, os municípios baixadianos respondiam por 37,8\% desse total. Passados 18 anos, a mesma região passou a representar $52,0 \%$ desse total, com 2.142. Desse modo, os crimes letais entre os municípios baixadianos ultrapassaram os dados referentes à cidade do Rio de Janeiro, tanto na relação por 100 mil habitantes quanto em números absolutos. Em 2019, em virtude do desmonte das Unidades de Polícia Pacificadoras e da política de segurança pública de "enfrentamento" encetada pelo governador Wilson Witzel, a cidade do Rio de Janeiro voltou a apresentar números absolutos de letalidade superior à Baixada Fluminense.

A despeito da disparidade criminal entre a Baixada Fluminense e a capital, a intervenção federal na área da segurança pública iniciada em 16/02/2018 e finalizada em 31 de dezembro daquele ano, despendeu efetivo mais numeroso de agentes e ações na cidade na cidade do Rio de Janeiro. A Figura 2 alude ao número de operações realizadas em cada município do estado durante o período da intervenção.

Figura 02 - Número de operações monitoradas durante a intervenção federal no estado do Rio de Janeiro

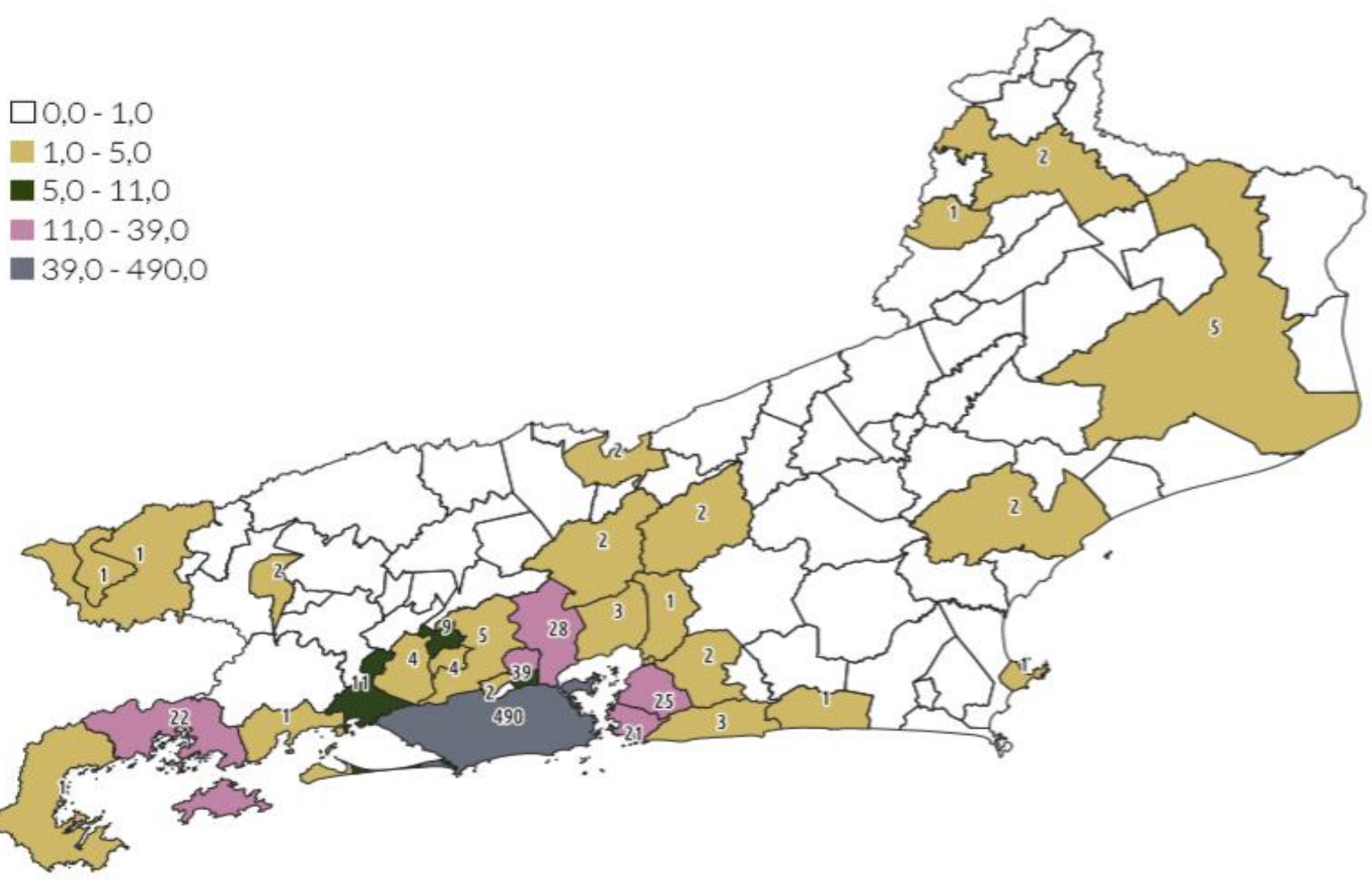

Fonte: Cesec (2019) 
As áreas dos municípios baixadianos objeto de operação policial foram majoritariamente apenas os municípios perpassado pela rodovia Presidente Dutra. A Figura 29 demonstra que Duque de Caxias e São João de Meriti totalizaram 67 operações policiais das 106 realizadas na Baixada Fluminense. Desse modo, esses dois municípios isoladamente concentraram 64\% das operações na sub-região. Nilópolis, município que não dispõe de nenhuma rodovia, não teve registrada nenhuma incursão policial no período da intervenção federal. Esses dados sugerem que tal escolha se deveu mais a posição geográfica dos municípios do que propriamente à proteção de seus moradores. Dessa forma, ficou evidenciado que os motivadores da intervenção federal estavam relacionados aos crescentes índices de roubos de cargas e aos constantes fechamentos de rodovias, algumas delas vitais para a dinâmica econômica da metrópole.

Os dados elevados relativos aos homicídios na Baixada Fluminense parecem ter menor relevância que a defesa da propriedade privada ou do bloqueio do fluxo de reprodução do capital, como acontece com o roubo de cargas e com o fechamento de rodovias. A preocupação maior não reside nas taxas de homicídios em si, mas na preocupação de alguém "morrer na contramão atrapalhando o tráfego".

Além dos dados referentes à taxa de letalidade, destacamos também as taxas de homicídios decorrentes de intervenção policial para analisar a natureza da violência na Baixada Fluminense. Ao contrário da primeira taxa analisada, os chamados autos de resistência para a Baixada Fluminense apresentavam números abaixo da média do estado entre 2000 e 2007. No ano seguinte e até 2011 fica acima da média e em 2012 volta a ficar abaixo. A partir deste ano as taxas de auto de resistência passaram a se manter acima da média estadual.

Em 2015 iniciaram uma tendência de elevação, a qual culminou em 2018 na mais elevada taxa registrada para este tipo de letalidade na Baixada Fluminense. No ano da intervenção militar no estado do Rio de Janeiro, a taxa de homicídios em razão de enfrentamentos policiais atingiu 14,3 para cada grupo de 100 mil residentes da Baixada Fluminense.

Apesar de ter um número populacional total equivalente a $58 \%$ de sua capital, em 2018 foram registrados 545 autos de resistência em municípios baixadianos contra 556 casos na cidade do Rio de Janeiro. Considerando os números absolutos desses dados, as taxas relativas aos autos de resistência sugeririam que essa tipologia de violência praticada pelas forças de segurança oficial vitimaria menos 
moradores da Baixada Fluminense. Todavia, quando essa equação passa a analisar tal taxa considerando o número de agentes públicos de segurança em atuação em cada Grande Região, esses dados ganham contornos ainda mais drásticos, pois, diferentemente de outros dados que compõem os índices de letalidade, os autos de resistência têm no policial o agente exclusivo de sua ação. Nesse sentido, embora seja importante a análise dessa tipologia criminal em relação ao total de residentes, igualmente é importante considerar o número de policiais em relação ao total de casos contabilizado.

A Tabela 3 sinaliza que em municípios baixadianos a relação de mortes por policiais lotados nos batalhões responsáveis pela área é maior do que nos demais municípios da RMRJ e na capital. Entre os municípios da Região Metropolitana do Rio de Janeiro, São Gonçalo foi o que apresentou o maior número absoluto de morte oriunda de intervenção policial, contudo, a maior média de autos de resistência para cada grupo de 100 policiais lotados corresponde ao batalhão de Belford Roxo, seguido pelo batalhão responsável pelos municípios de Seropédica, Itaguaí, Paracambi, Queimados e Japeri. Em ambos os batalhões, para cada grupo de 100 policiais militares lotados, houve cerca de 30 casos de resistência. No outro extremo estatístico da RMRJ estão os municípios de Magé e Guapimirim com apenas 6 casos para cada 100 policiais e com 18 autos de resistência no total.

Tabela 03 - Relação entre policiais militares lotados por batalhão e população atendida entre os municípios da RMRJ - 2018

\begin{tabular}{|c|c|c|c|c|c|}
\hline \multirow[b]{2}{*}{ Municípios } & \multirow{2}{*}{$\begin{array}{l}\text { Policiais } \\
\text { Militares } \\
\text { lotados }\end{array}$} & \multirow{2}{*}{$\begin{array}{l}\text { População } \\
\text { total } \\
\text { atendida } \\
\text { pelo BPM }\end{array}$} & \multicolumn{3}{|c|}{ Autos de resistência } \\
\hline & & & Total & $\begin{array}{c}\text { Taxa por } \\
100 \text { mil } \\
\text { hab. }\end{array}$ & $\begin{array}{c}\text { Taxa para } \\
\text { cada } 100 \\
\text { policiais }\end{array}$ \\
\hline Belford Roxo & 306 & 495.783 & 93 & 18,75 & 30,39 \\
\hline Duque de Caxias & 781 & 890.997 & 146 & 16,38 & 18,69 \\
\hline Magé e Guapimirim & 373 & 295.341 & 18 & 6,09 & 4,82 \\
\hline Niterói e Maricá & 979 & 652.036 & 75 & 11,50 & 7,66 \\
\hline $\begin{array}{l}\text { Nova Iguaçu, Mesquita e } \\
\text { Nilópolis }\end{array}$ & 938 & 1.128 .256 & 104 & 9,21 & 11,08 \\
\hline São Gonçalo & 875 & 1.049 .826 & 166 & 15,81 & 18,97 \\
\hline São João de Meriti & 458 & 460.461 & 45 & 9,77 & 9,82 \\
\hline
\end{tabular}


Seropédica,

Paracambi, Queimados e

453

503.855

130

25,80

28,69

Japeri

Cachoeiras de Macacu,

Tanguá, Rio Bonito e Itaboraí

$462 \quad 380.684$

36

9,45

7,79

\begin{tabular}{lrrrrrr}
\hline Baixada Fluminense & & 3.309 & 3.774 .692 & 536 & 14,19 & 16,19 \\
$\begin{array}{l}\text { Demais municípios da } \\
\text { RMRJ }\end{array}$ & 2.316 & 2.082 .546 & 277 & 13,30 & 11,96 \\
$\begin{array}{l}\text { Rio de Janeiro } \\
\text { n }\end{array}$ & & 8.151 & 6.520 .266 & 556 & 8,52 & 6,82
\end{tabular}

Fonte: Elaborado pelo autor a partir de dados do Instituto de Segurança Pública (ISP-RJ, 2020) e IBGE (2017)

A análise desses dados para além da escala municipal revela a dessimetria entre as partes componentes da RMRJ. Na cidade do Rio de Janeiro, em 2018 ocorreram em média 8,52 autos de resistência para cada 100 policiais, na Baixada Fluminense esse número chegou a 14,19, enquanto nos demais municípios metropolitanos atingiu 13,3. Grosso modo, a análise sugere que os policiais em atuação na Baixada Fluminense apresentam um grau de letalidade superior aos demais policiais lotados em outras partes do estado do Rio de Janeiro como um todo. Nesse sentido, o comparativo entre a Baixada Fluminense e a cidade do Rio de Janeiro indica que há 38,5\% mais autos de resistência por policiais lotados em municípios baixadianos que na metrópole carioca. Embora o perfil desse grupo paramilitar tenha sofrido uma alteração ao aceitar ex-traficantes, esses grupos ainda hoje são compostos majoritariamente por policiais e ex-policiais.

\section{Considerações finais}

O processo de ocupação populacional da Baixada Fluminense, encetado a partir das demandas socioeconômicas da cidade do Rio de Janeiro se efetivou de modo atabalhoado para o espaço baixadiano. As populações foram alocando-se em propriedades com notáveis deficiências, originárias de loteamentos privados, os quais posteriormente foram recebendo intervenções públicas. Contudo, as mazelas sociais que hoje afligem alguns municípios baixadianos, não podem ser imputadas inequivocamente à eventual predileção dada à cidade do Rio de Janeiro nas formulações de políticas públicas. Entretanto, o entendimento referente ao processo histórico de ocupação populacional da região, sua importância e configuração 
socioeconômica no momento atual, só têm sentido se compreendidos no âmbito da RMRJ. Como efeito dessa retroalimentação, o papel desempenhado pela cidade do Rio de Janeiro na conjuntura nacional e internacional, reflete o papel imposto à Baixada Fluminense na conjuntura metropolitana.

Apesar desse vínculo, as questões que assolam a Baixada Fluminense parecem não terem relação com o Rio de Janeiro. Desse modo, a RMRJ existe enquanto realidade econômica por meio dos fluxos econômicos e de trabalhadores, contudo problemas como a violência dizem respeito somente aos municípios baixadianos. É como se fosse outro espaço, externo e longínquo composto por outra "categoria" de pessoas. Essa construção simbólica, eivada de geografia imaginativa, singulariza a Baixada Fluminense como um território produzido e condicionado a partir da violência.

Em um primeiro momento a violência na Baixada Fluminense reflete uma relação de produção de conotação ruralista. O alcance da violência foi intensificado a partir do adensamento populacional da região e seu processo de incorporação imobiliária à malha urbana da cidade do Rio de Janeiro. Desse modo, as sanções físicas conhecem sua primeira mudança ao passar "do restrito emprego oligárquico dos senhores ou dos políticos na superação dos seus impasses, a violência passará a ser aplicada pelas empresas incorporadoras no gerenciamento dos seus problemas econômicos derivados da ocupação do solo" (ALVES, 2003, p. 60-61). Em seguida, a partir dos anos 1990, a violência atinge um grau mais elevado de sofisticação ao infiltrar agentes ligados a ela nos legislativos e executivos dos municípios da Baixada Fluminense.

O prestígio alcançado no combate à "violência" utilizando-se de uma violência ainda maior, como é a supressão da vida de outra pessoa, permitiu a alguns agentes imputarem o "medo" a uma parcela da população e o "respeito" a parcela restante que aprova o modus operandi desses grupos. Sendo pelo medo imposto ou pelo respeito alcançado, as duas acepções favoreceram seus processos políticos no legislativo e no executivo. Esse processo, em alguma medida, encontra exemplos na cidade do Rio de Janeiro. Contudo, em razão da dinâmica mais complexa da capital fluminense, essas representações paramilitares embora consigam alcançar de forma direta o poder legislativo, têm sua força política diluída frente a outros agentes. $\mathrm{Na}$ Baixada Fluminense, por sua vez, esses grupos violentos podem se desenvolver politicamente sem nenhum contraponto significativo, pois além de se constituírem a 
partir da violência, em alguns municípios os grupos paramilitares são, também, a principal força econômica local.

A condição financeira desses grupos permite, com maior facilidade, sua infiltração também no poder judiciário. Assim, junto ao medo imposto pela violência, a esses grupos somam-se ainda a "legitimação" obtida pelos cargos públicos eletivos ocupados e a "compra" de parte do judiciário. Essa articulação, a qual consiste em um fenômeno peculiar à Baixada Fluminense no tocante à sua eficácia e extensão, fornece indícios para o entendimento da região como lócus da violência por excelência.

Cumpre acentuar, mais uma vez, que a disseminação da violência se opera em paralelo às ineficientes políticas públicas destinadas à Baixada Fluminense para além da área de segurança. Essa configuração atraiu população de baixo status social, resultando em processo exitoso de periferização da Baixada Fluminense. Essa mesma periferia, na qual agentes públicos de segurança podem agir às margens das leis com o respaldo de parte da população, também é preterida em ações governamentais. No tocante às políticas públicas, a relação entre policiais militares e a população atendida no interior da RMRJ expõe que o descaso relativo à área de segurança não condiz a um fenômeno recente e tampouco restrito a projetos específicos como as UPPs. Ao contrário, a ineficiência operacional das forças de segurança consiste em um processo histórico, o qual contribui para criar um estigma sobre os municípios baixadianos. Com efeito, o adensamento populacional desordenado, o qual atraiu população de baixo perfil socioeconômico, aliado às políticas públicas de segurança deficitária, concorreram para produzir no imaginário social, nacional e fluminense, uma periferia por excelência.

Essa construção imagética foi plasmada a partir do somatório de uma região violenta habitada, majoritariamente, por uma população empobrecida. Cabe ainda ressaltar que a Baixada Fluminense não existe oficialmente enquanto Região Administrativa de governo. Contudo, quando a Secretaria de Segurança Pública a institui como uma região, tal fato assinala que sua existência só ganha contornos de "realidade" se entendida a partir das atrocidades criminais que vitimizam seus moradores. Desse modo, a violência oficializa esta região para os órgãos governamentais. 
Como arremate da questão em tela, queremos ressaltar que em uma Região Metropolitana, na qual o fluxo entre suas partes integrantes é intenso, o núcleo naturalmente concentra a maior parte dos postos de trabalho. Por essa razão, o fortalecimento das políticas de segurança na cidade do Rio de Janeiro, em alguma medida, protege o morador da Baixada Fluminense que se desloca para o trabalho. Nesse raciocínio residiria a explicação para o número de policiais considerados ideal na capital ser mais elevado que na Baixada Fluminense. Contudo, não deve apenas sua condição de reprodutor do sistema econômico vigente, expresso na categoria de trabalhador, deve ser protegida. Antes de fazer a roda econômica girar, o morador da Baixada Fluminense necessita fazer sua vida acontecer, pois mesmo sendo peça central da maquinaria capitalista, eles são insubstituíveis para seus entes e amigos e essa condição deve, também, ser objeto de ações públicas de segurança por parte do Estado.

\section{Referências bibliográficas}

ALBUQUERQUE, Enderson. A promessa e a ameaça - o funcionamento da violência como ferramenta política na Baixada Fluminense. GEOgraphia. Niterói, Universidade Federal Fluminense, UFF, Ano 22, n.48, 2020.

ALVES, José Cláudio Souza. Baixada Fluminense: a violência na construção de uma periferia. [S.L.: s.n.], 1994.

ALVES, José Cláudio Souza. Dos Barões ao Extermínio: Uma História da Violência na Baixada Fluminense. Duque de Caxias, RJ: APPH-CLIO, 2003.

ALVES, José Cláudio Souza. Violência e política na Baixada: o caso dos grupos de extermínio. In: Documento Impunidade na Baixada Fluminense. Rio de Janeiro: [s.n.], 2005.

ALVES, José Cláudio Souza. Baixada Fluminense: reconfiguração da violência e impactos sobre a educação. Revista Movimento. Niterói, Faculdade de Educação-Programa de Pósgraduação em Educação, UFF, Ano 2, № 3, 2015.

CESEC. INTERVENÇÃO FEDERAL: um modelo para não copiar. Rio de Janeiro: [s.n.], 2019.

FORÚM BRASILEIRO DE SEGURANÇA PÚBLICA. Anuário Brasileiro de Segurança pública 2019. http://www.forumseguranca.org.br/wp-content/uploads/2019/09/Anuario-2019FINAL-v3.pdf. Acesso em: 24 ago. 2020.

IBGE. Estimativas populacionais para os municípios e para as Unidades da Federação brasileiros. 2017.

ISP-RJ. Séries históricas anuais de taxa de letalidade violenta no estado do Rio de Janeiro e grandes regiões. Rio de Janeiro: [s.n], 2020. Disponível em:

http://www.ispdados.rj.gov.br/Arquivos/SeriesHistoricasLetalidadeViolenta.pdf. Acesso em: 30 mar. 2020. 
ODALIA, Nilo. O que é violência. São Paulo: Editora Brasiliense, 1991.

OLIVEIRA, Raimundo Jovanil Pereira. Do medo da violência à violência do medo: uma reflexão sobre os impactos sócio-político-espaciais da violência em Fortaleza. 2016. 117 f. Dissertação de mestrado. Centro de Humanidades, Mestrado Acadêmico em Políticas Públicas e Sociedade, Universidade Estadual do Ceará, Fortaleza, 2016.

RIBEIRO, Eduardo; CANO, Ignacio; SENTO-SÉ, João Trajano; LÁZARO, Márcio. A incidência da violência na Baixada Fluminense. In: Documento Impunidade na Baixada Fluminense. Rio de Janeiro: [s.n.], 2005.

STOPPINO, Mário. Violência. In. BOBBIO, Norberto; MATTEUCCI, Nicola; PASQUINO, Gianfranco. Dicionário de Política. Vol. 1. Brasília: Editora UNB, 1998.

ZALUAR, Alba. Um debate disperso: violência e crime no Brasil da redemocratização. In: São Paulo em perspectiva, São Paulo, v. 13, n. 3, p. 3-17, set.1999.

\section{NOTAS DE AUTOR}

\section{CONTRIBUIÇÃO DE AUTORIA}

Enderson Albuquerque - Concepção. Coleta de dados, Análise de dados, Elaboração do manuscrito, revisão e aprovação da versão final do trabalho

\section{FINANCIAMENTO}

Não se aplica.

\section{CONSENTIMENTO DE USO DE IMAGEM}

Não se aplica.

\section{APROVAÇÃO DE COMITÊ DE ÉTICA EM PESQUISA}

Não se aplica.

\section{CONFLITO DE INTERESSES}

Não se aplica.

\section{LICENÇA DE USO}

Este artigo está licenciado sob Licença Creative Commons CC-BY. Com essa licença você pode compartilhar, adaptar, criar para qualquer fim, desde que atribua a autoria da obra.

\section{HISTÓRICO}

Recebido em: 16/04/2020

Aprovado em: 26/08/2020 